\title{
Closure of a persistent gastric leak using a cardiac septal occluder
}

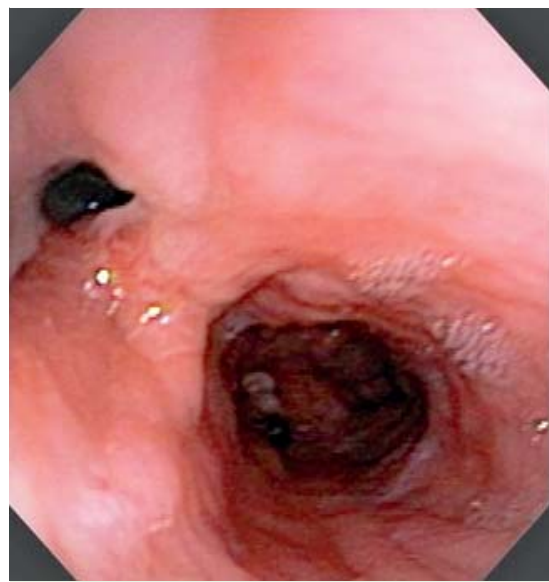

Fig. 1 Anastomotic leak site immediately distal to the gastroesophageal junction along the staple line.

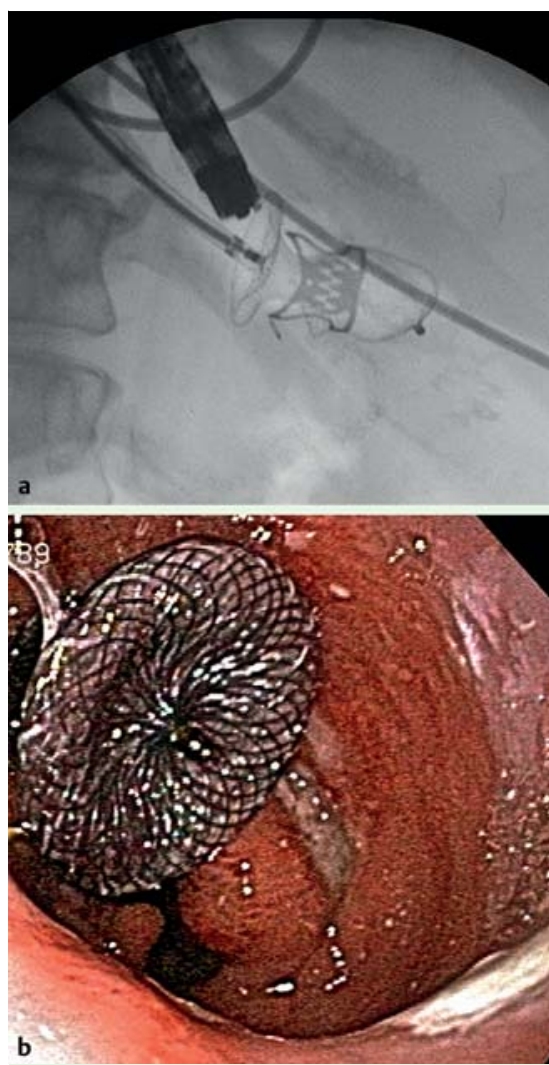

Fig. 3 Deployment of the cardiac septal occluder. a Fluoroscopic image during deployment of the cardiac septal occluder. The previously placed over-the-scope clip remains. b Endoscopic view of the occluder device after deployment.

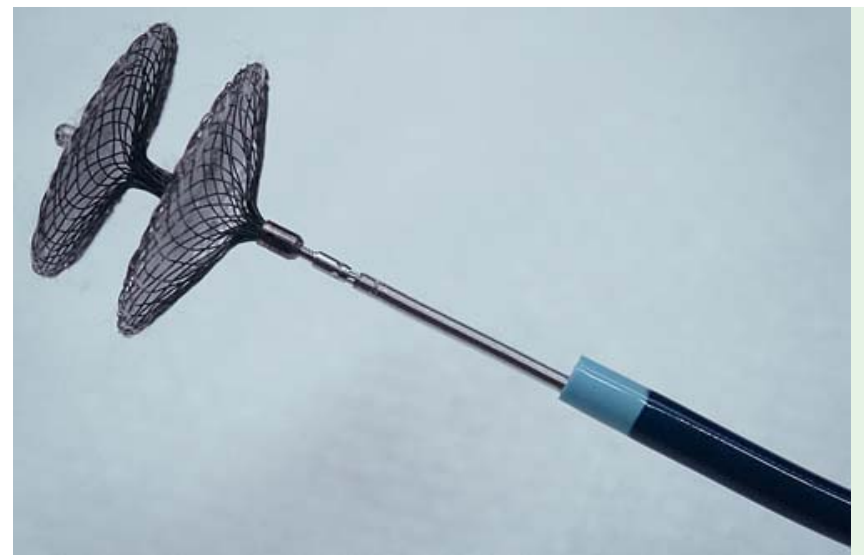

Fig. 2 The Amplazter cardiac septal occluder device.

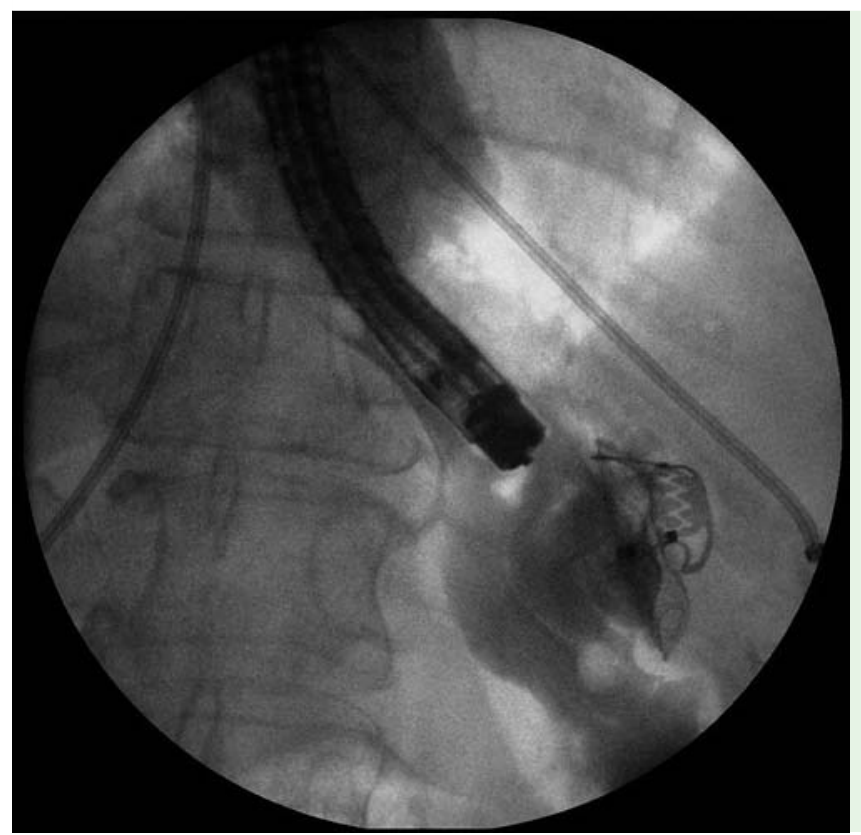

Fig. 4 Fluoroscopic image 8 weeks postinsertion showing complete closure of the leak.

Anastomotic leaks occur in up to $5 \%$ of patients who undergo bariatric surgical procedures [1]. Reoperation is associated with a high morbidity, and a mortality of up to $10 \%$ [2]. Therefore, endoscopic management should be considered in the first instance. We present a case of a gastric anastomotic leak that was successfully closed with a cardiac septal occluder device (Amplatzer; St. Jude Medical, Plymouth, Minnesota, USA).

A 50-year-old woman was admitted with tachycardia, fever, and vomiting 4 weeks after laparoscopic vertical sleeve gastrectomy. Abdominal computed tomography revealed a $6-\mathrm{cm}$ collection lateral to the gastroesophageal junction. Percutaneous drain insertion did not result in clinical improvement.
Esophagogastroduodenoscopy (EGD) revealed a $6 \times 4$-mm leak immediately distal to the gastroesophageal junction along the staple line ( $\bullet$ Fig. $\mathbf{1})$. Over-the-scope clip placement (Ovesco Endoscopy AG, Tübingen, Germany), fully-covered selfexpandable esophageal stent insertion, and endoluminal suturing (Overstitch, Apollo Endosurgery, Austin, Texas, USA) all failed to achieve closure.

Therefore, closure was pursued using the cardiac septal occluder. The device is a self-expandable double umbrella-shaped

\section{Video 1}

Video demonstrating the occluder device, its deployment, and follow-up at 8 weeks. 
polyester-covered nitinol wire mesh (๑ Fig. 2). A 12-Fr delivery catheter $(80 \mathrm{~cm}$ in length) was inserted over a guidewire placed through the leak. The guidewire was removed and the deployment catheter (preloaded with the cardiac septal occluder) was inserted through the delivery catheter. The endoscope was placed alongside the catheter and an endoscopist deployed the cardiac septal occluder under endoscopic and fluoroscopic visualization ( Fig.3). The total procedure time was 9 minutes.

The patient showed rapid clinical improvement, and the percutaneous drain was removed after 1 week. Repeat EGD at 8 weeks revealed no epithelializaton of the device, and contrast injection demonstrated no leak ( $\bullet$ Fig.4).

This case demonstrates a novel, yet simple method of managing a postbariatric surgical anastomotic leak using a cardiac septal occluder. There are reports of successful use of this device in closing tracheoesophgaeal and gastrocolonic fistulae [3,4]. Of note, in contrast to the intravascular space, epithelialization does not appear to occur in the gastrointestinal tract. However, our intention is for the device to remain permanently in situ. Migration of the device has been reported with potentially serious consequences and therefore it should be used only as a salvage therapy [5].

\section{Endoscopy_UCTN_Code_TTT_1AO_2AI}

Competing interests: $P$. Saxena has received consulting fees from Boston Scientific and has received research support from Cook Medical.

\section{Vivek Kumbhari, Andrew C. Storm, Payal Saxena, Patrick I. Okolo}

Division of Gastroenterology and Hepatology, Department of Medicine, The Johns Hopkins Medical Institutions, Baltimore, Maryland, USA

\section{References}

1 Morales M, Miedema B, Scott J et al. Management of post surgical leaks in the bariatric patient. Gastrointest Endosc Clin N Am 2011; 21: 295-304

2 Kumar N, Thompson C. Endoscopic management of complications after gastrointestinal weight loss surgery. Clin Gastroenterol sHepatol 2013; 11: 343-353
3 Repici A, Presbitero P, Carlino A et al. First human case of esophagotracheal fistula closure by using a cardiac septal occluder (with video). Gastrointest Endosc 2010; 71: 867-869

4 Lee HJ, Jung ES, Park MS et al. Closure of a gastrotracheal fistula using a cardiac septal occluder device. Endoscopy 2011; 43 (Suppl. 02): E53-54

5 Coppola F, Boccuzzi G, Rossi G et al. Cardiac septal umbrella for closure of a tracheoesophageal fistula. Endoscopy 2010; 42 (Suppl. 02): E318-319

\section{Bibliography}

DoI http://dx.doi.org/

10.1055/s-0034-1364948

Endoscopy 2014; 46: E147-E148

(c) Georg Thieme Verlag KG

Stuttgart · New York

ISSN 0013-726X

\section{Corresponding author}

Patrick I. Okolo III, MD

Division of Gastroenterology and Hepatology

Department of Medicine

Johns Hopkins Hospital

1800 Orleans St, Suite 7125 G

Baltimore, MD 21205

USA

Fax: +1-410-502-7010

pokolo2@jhmi.edu 